\title{
Outros concretismos: desdobramentos entre Amílcar de Castro, Lygia Clark, Wlademir Dias-Pino, conceitualistas e minimais
}

Letícia Féres I UFMG/CNPq Michel Mingote I UFMG/CNPq Vera Casa Nova I UFMG/CNPq

Resumo: Este artigo analisa as relações entre o Poema Processo (Solida) e as experiências neoconcretas de Lygia Clark e Amilcar de Castro.

Palavras chave: concretismo, artes neo-concretas, poema concreto.

"... e nada melhor do que ser-se sendo o outro." Lygia Clark, em carta para Hélio Oiticica

No conceitualismo, como em outras vanguardas modernas, a mística em torno do objeto artístico único foi desprezada e chegou-se mesmo a afirmar, como o fez Donald Judd - artista inserido nos processos artísticos minimalista e conceitual -, que "Se alguém diz 'isto é arte', isto é arte". Assim, 
o objeto artístico não é mais importante que a idéia encerrada em sua execução: em A Arte do Conceito, Harry Flynt indica que "Como os conceitos têm íntima ligação com a linguagem, a arte do conceito é uma espécie de arte da qual o material é a linguagem". Lawrence Weiner, um dos principais nomes dessa vanguarda, não se opunha que suas propostas fossem executadas por outrem ou por ninguém; isso só competia ao fruidor da obra.

O poema processo criou o conceito de "versão", entendido como a possibilidade de que o consumidor do objeto artístico recrie o processo de criação do autor, apropriando-se dessa lógica, reconfigurando-a, à sua maneira. O leitor, assim, participa da criação da obra e transforma-se também em autor. "Versão" se relaciona à idéia de arte para domínio público, dos conceitualistas. As idéias de Lawrence Weiner e Dias-Pino são similares: "Depois que você tomar conhecimento de uma obra minha, você é dono dela", conforme Weiner; "O poema se faz com o processo e não com palavras", disse o fundador do poema processo.

Artistas minimalistas denominam seus objetos como specifc objects, de forma a eliminar toda ilusão sobre a possibilidade de interpretação. Ao impor objetos ditos específicos não há mais possibilidade de que sejam criados jogos de significação e, assim, os objetos apresentam-se sem equívocos, reduzidos "à simples formalidade de sua forma, à simples visibilidade de sua configuração visível, oferecido[s] sem mistério, entre linha e plano, superfície e volume", conforme Didi-Huberman indica em O que Vemos, o que Nos Olha. Essa idéia é explicitada pelos paralelepípedos de Donald Judd, pois neles o que você vê é apenas o que você vê, ou seja, um paralelepípedo.

Para o poema processo a obra só adquire sentido se for apropriada pelo espectador/ fruidor (no caso dos conceitualistas nem seria necessária a concreção da idéia: bastaria que a idéia ocorresse na mente do artista para chegar ao estatuto de arte). A importância da participação do fruidor para a construção do objeto artístico também foi apresentada por Ferreira Gullar, na Teoria do Não-Objeto: "A mera contemplação não basta para revelar o sentido da obra - e o espectador passa da contemplação à ação. Mas o que a sua ação produz é a obra mesma".

Lygia Clark - artista que assinou o Manifesto Neoconcreto, ao lado de Amílcar de Castro e Ferreira Gullar, entre ouros -, com seus Bichos, e Wlademir Dias-Pino, com Solida, criam textos em que o gesto, o manuseio, o tatear, é a linguagem pressuposta para a leitura, entendida aqui como uso, consumo, transformação. 
Vistos de longe os Bichos são apenas bonitos - talvez estranhos planos de alumínio, embora já apresentem a potência da flexibilidade, dada pelas suas dobradiças. Por meio da leitura, o alumínio, material duro, torna-se uma estrutura algo flexível, que pode adquirir as mais variadas formas, dependendo do desejo do fruidor e a do próprio objeto, que também possui um movimento próprio: as dobradiças assistirão a liberdade do leitor em manipular essas estruturas abertas.

Solida pode parecer ininteligível num primeiro olhar. Mas com a manipulação do livro pelo fruidor, as significâncias vão se abrindo. O olho que acompanha o gesto desdobra as potências do texto e reformula diversas possibilidades de significados, a partir de uma matriz lingüística que vai se reprocessando em diversas outras. Em Solida, o "poema palavra-livro", a idéia conceitualista de palavras tornadas imagens é levada à radicalidade: a palavra se transforma e o poema é feito apenas por vírgulas; em outro momento, apenas por código de barras, gráficos ou por imagens que lembram as pinturas de Volpi. A palavra dobra sobre si mesma e sobre o papel e traça outras possibilidades de leitura que permitirão ao leitor percorrer outros caminhos que não somente os indicados pelos gráficos. Tal ato revelará o apagamento da leitura e da palavra. Solida aproxima-se, ao mesmo tempo, da caligrafia, das artes gráficas, da tipografia e também da escultura - quando o poemanão-mais-palavra, mas pura estrutura dobrada e dobrável, à maneira de um origami, ergue-se do papel. Isso também se relaciona à idéia minimalista do objeto específico.

Os Bichos e Solida não se definem como objetos, obras, livrospoemas, esculturas, mas se fazem num lugar fora dos limites convencionais da arte e em que esses conceitos se agrupam. Eles não mais são, mas fazemse, tornam-se, pela leitura: o objeto só existe "através das suas metamorfoses ou na declinação dos seus perfis", como Gilles Deleuze escreve em A Dobra. Pode-se dizer que os Bichos e Solida tornam-se objetos especiais, como sugere Gullar. E, ainda de acordo com Deleuze, "não se define[m] por uma forma essencial, mas atinge[m] uma funcionalidade pura, declinando uma família de curvas enquadradas por parâmetros, inseparáveis de uma série de declinações possíveis ou de uma superfície de curvatura variável que ele[s] próprio[s] descreve[m]". Bichos e Solida não foram criados como imitação do mundo ou para se inserir em um espaço: eles apresentam um mundo e fundam um novo espaço ao se presentificarem. 
Didi Huberman aponta que na operação tautológica "o que você vê é o que você vê", dos minimalistas, dos paralelepípedos de Judd e dos cubos "simples", "específicos" de Tony Smith, o que vemos "só vale - só vive - em nossos olhos pelo que nos olha". Ou seja, as imagens da arte - por mais "simples" e "minimais" que sejam sabem "apresentar a dialética visual desse jogo no qual soubemos (mas esquecemos de) inquietar nossa visão e inventar lugares para nossa inquietude." As imagens da arte colocam-nos diante de objetos de perda, e não apenas daqueles que possuímos, que apreendemos pelo olhar. Esses outros objetos nos abrem para a capacidade de jogar a tragédia do visível e do invisível, objetos que apresentam imagens dialéticas.

No processo de apagamento de leitura proposto por Dias-Pino, em Solida, percebe-se o lugar para essa inquietação da visão. O jogo que leva em conta a participação do leitor, que desencadeia novos processos, é o jogo que abre para a vocação essencial de toda superfície que nos olha, isto é, "de toda superfície que nos concerne para além de sua visualidade evidente, sua opticidade ideal e sem ameaça”, nas palavras de Didi-Huberman. A manipulação, em Solida, chega ao gesto que se surpreende ao se deparar com aquilo que se aproxima de esculturas como as de Amílcar de Castro.

Essa aproximação é possível não apenas pela forma, mas também pelo processo que encerra, explicitado pelo que o artista mineiro diz: "A superfície é domada - é partida e vai sendo dobrada - é quando, e por fatalidade o espaço se integra criando o não-previsto. É pura surpresa. É como um gesto inesperado. Um gesto espontâneo. Espontâneo como se fosse o primeiro aquele que fundamenta a comunhão com o futuro."

Ao mesmo tempo em que o leitor desloca as estruturas desses objetos, ele mesmo é retirado de seu lugar habitual. Agora não apenas o objeto é dobrado, mas o próprio fruidor torna-se uma dobra possível do objeto, e vice-versa. Cada um se faz, fazendo-se, ao mesmo tempo, leitor e leitura, por meio do outro. Não há mais como discerni-los, transformados agora nessa outra estrutura móvel, o fruidor-objeto. Somente a partir dos deslocamentos de ambos é que significações são possíveis.

Assim como a noção de objeto artístico, o sujeito também aparece em outro estatuto: a escultura sem pedestal, a pintura fora do quadro, a poesia fora do papel e da palavra, o leitor que é autor, o ledor que é leitura. Esta não mais ocorre a partir de um ponto de vista, mas só ocorre porque o 
leitor está, conforme Deleuze, instalado no ponto de vista, desterritorializado como sujeito. Ele também é o texto, é a nova estrutura.

A partir do saber propiciado pelo contato com o livro, o leitor se reconfigura, deslocado no espaço e no tempo, que agora é o da recriação da lógica do livro. "Tudo se dobra a sua maneira", diz Deleuze. Da mesma forma, o leitor se torna a dobradiça fundamental dos Bichos e, talvez, o processo último de Solida.

Resumé: Cet article analyse les relations entre le Poème Procès (Solida) et les expériences neoconcrètes de Lygia Clark et Amilcar de Castro. Mots clés: Lygia Clark, Amilcar de Castro, Poème Procès.

$$
\text { Referências Bibliográficas }
$$

CASTRO, Amílcar de. In: AMARAL, Aracy Abreu (Org.). Projeto Construtivo na Arte: 19501962. Rio de Janeiro: Museu de Arte Moderna; São Paulo: Pinacoteca do Estado, 1977.

CLARK, Lygia. Bichos. In: AMARAL, Aracy Abreu (Org.). Projeto Construtivo na Arte: 19501962. Rio de Janeiro: Museu de Arte Moderna; São Paulo: Pinacoteca do Estado, 1977. p. 248.

CLARK, Lygia; OITICICA, Hélio. Cartas, 1964-74. Luciano Figueiredo (Org.). Rio de Janeiro: UFRJ, 1998.

DELEUZE, Gilles. A Dobra: Leibniz e o Barroco. São Paulo: Papirus, 2000.

DEMPSEY, Amy. Arte Conceitual. In: Estilos, Escolas \& Movimentos: Guia Enciclopédico da Arte Moderna. São Paulo: Cosac \& Naify, 2003. p. 240-243.

DIAS-PINO, Wlademir. Solida. [s.l.]: Edição do Autor, 1955.

DIAS-PINO, Wlademir. Processo: Linguagem e Comunicação. Petrópolis: Vozes, 1971.

DIDI-HUBERMAN, George. O que Vemos, O que Nos Olha. São Paulo: Editora 34, 1998.

GULLAR, Ferreira. Teoria do Não-Objeto. In: Etapas da Arte Contemporânea: do Cubismo à Arte Neoconcreta. Rio de Janeiro: Revan, 1999. 289-301.

SMITH, Roberta. Arte Conceitual. In: STANGOS, Nikos (Org.). Conceitos da Arte Moderna. Rio de Janeiro: Jorge Zahar, 2000. p.182-191. 
O eixo e a roda: $v$. 13, 2006

Disponível em: bttp://www.letras.ufmg.br/poslit

Anexo

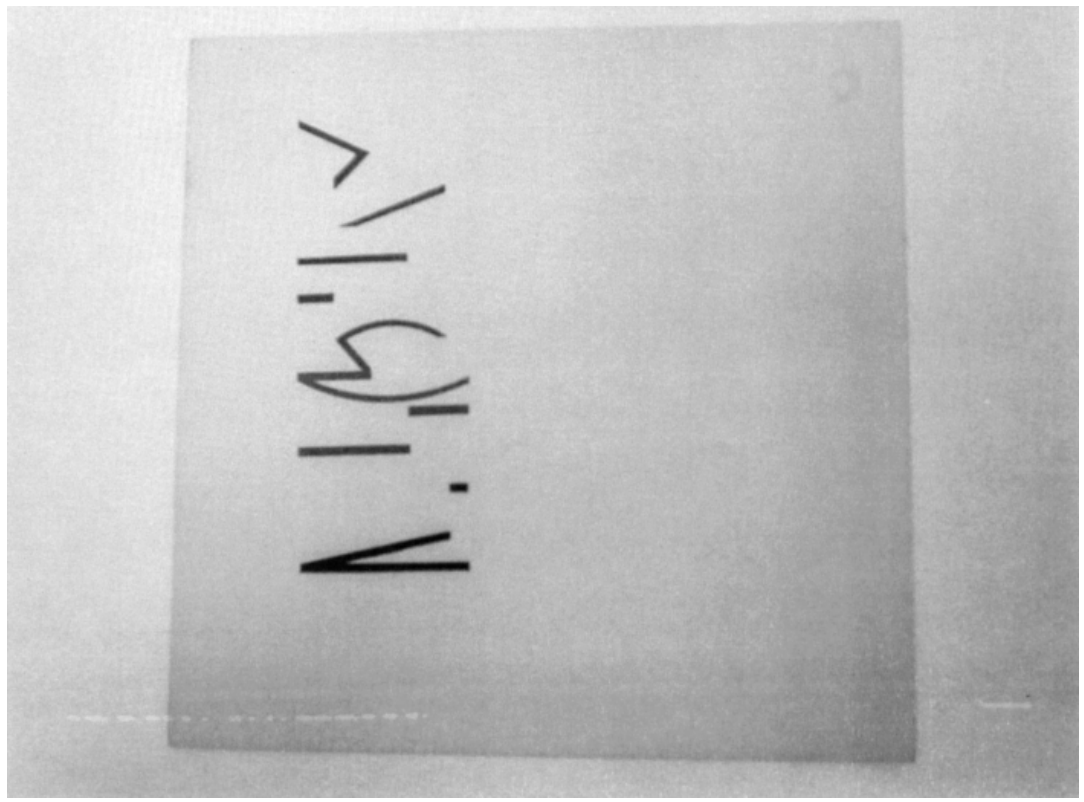

Figura 1

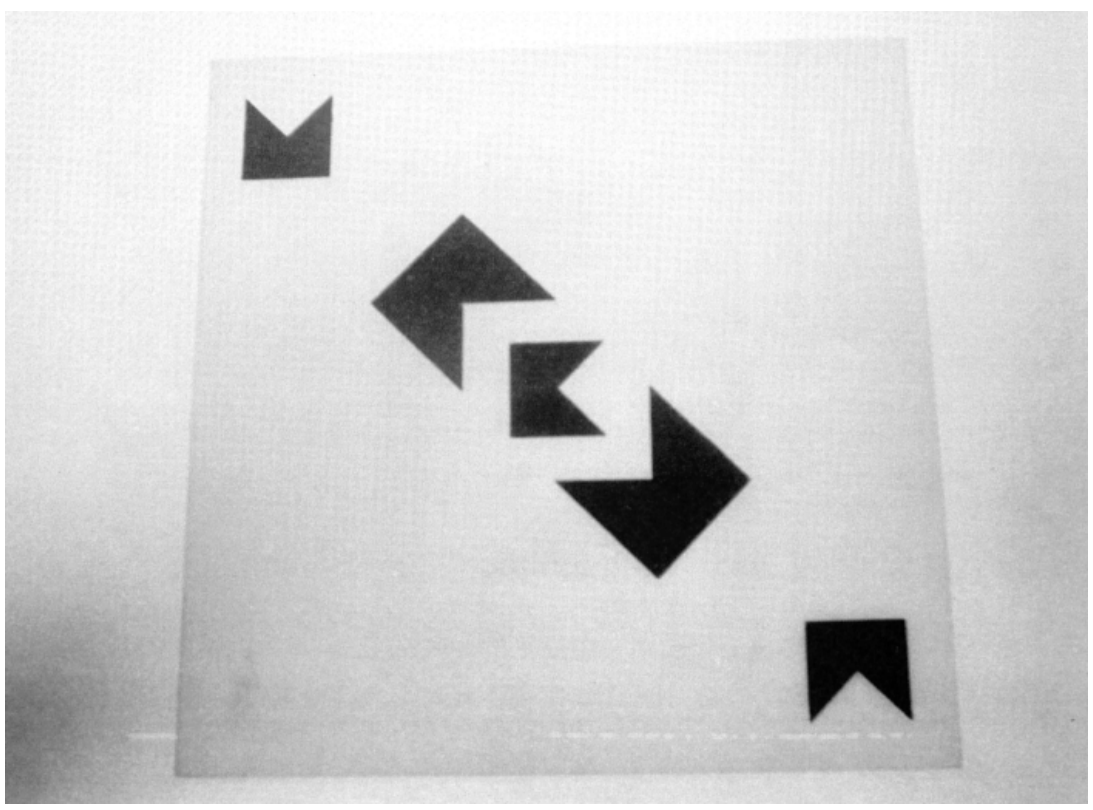

Figura 2 
Belo Horizonte, p. 1-232

Disponível em: http://www.letras.ufmg.br/poslit

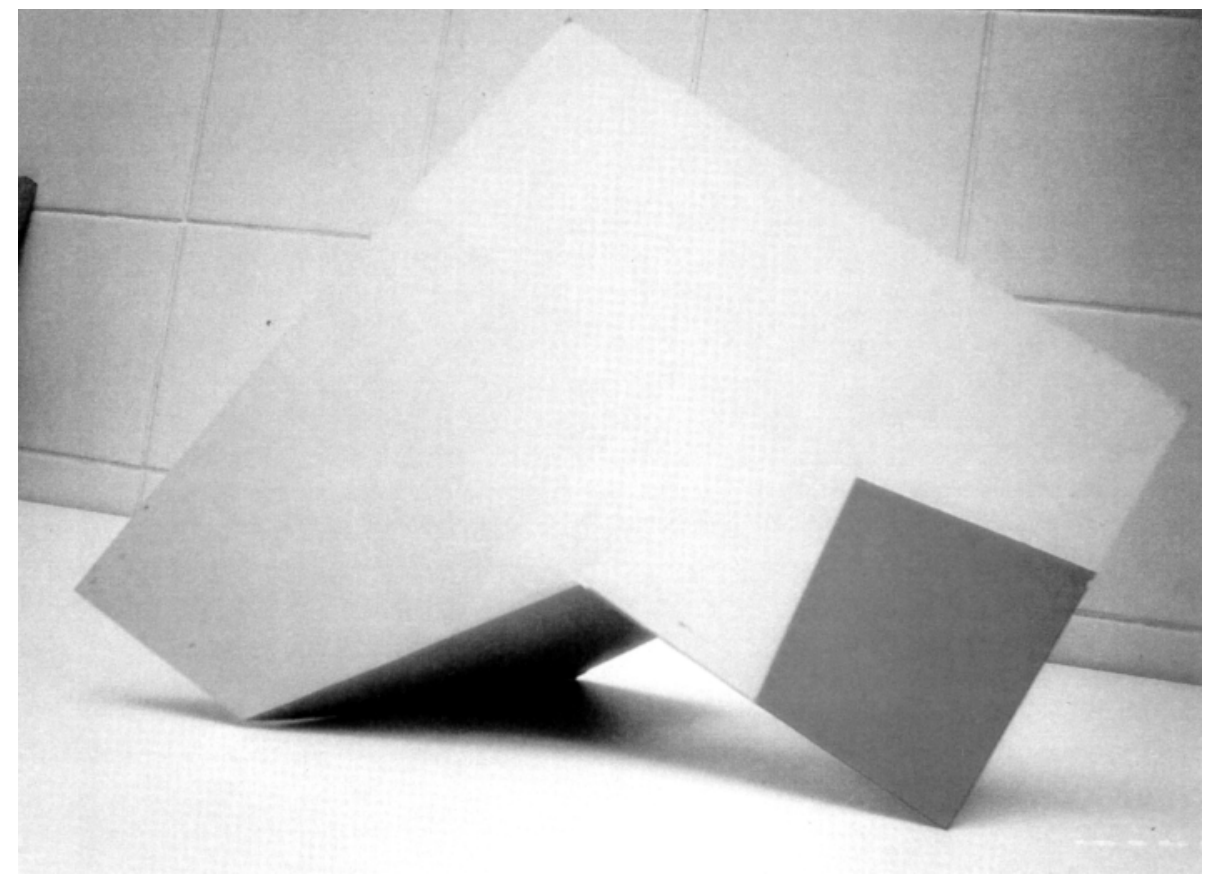

Figura 3 
O eixo e a roda: $v$. 13, 2006

Disponivel em: bttp://www.letras.ufmg.br/poslit

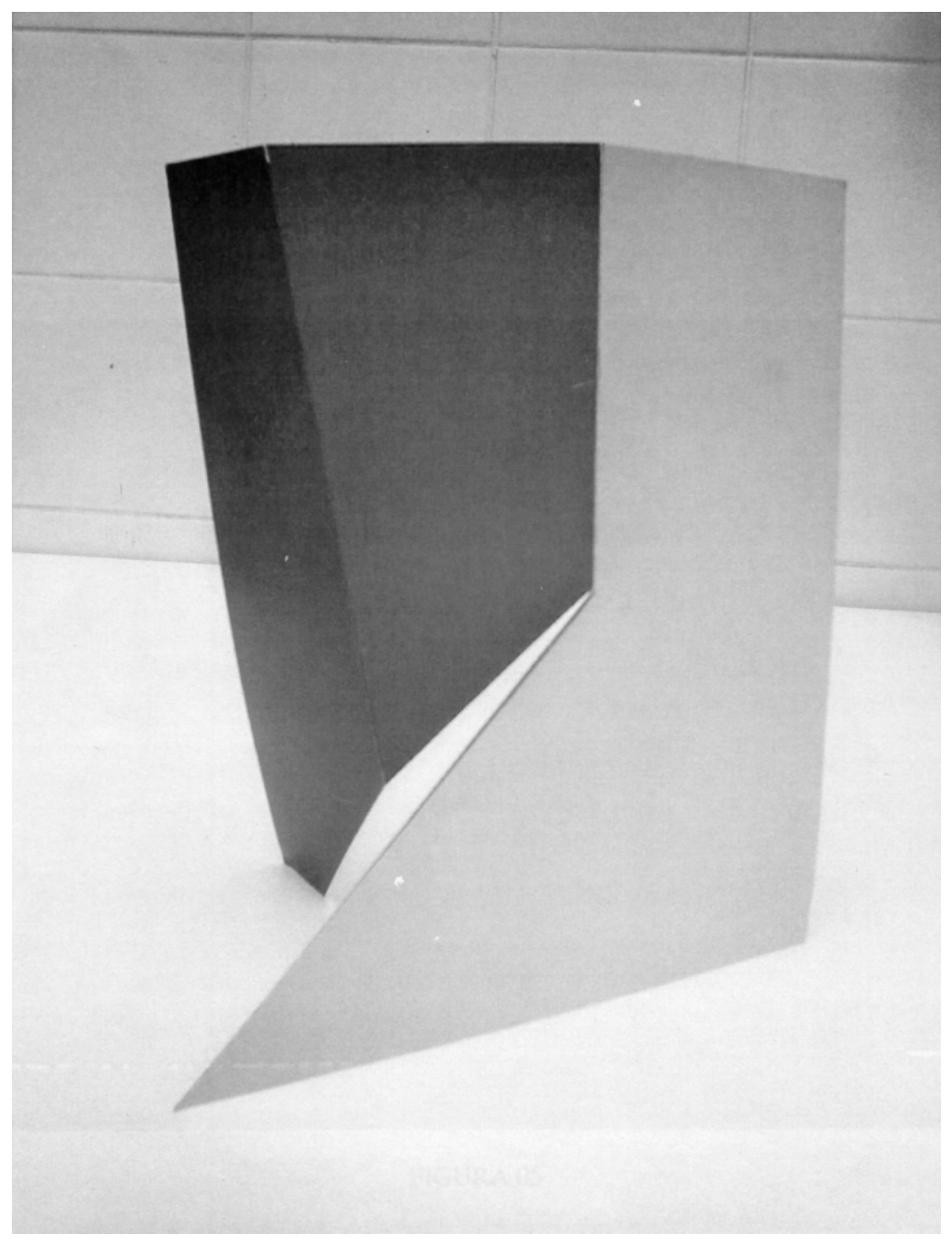

Figura 4 
Belo Horizonte, p. 1-232

Disponível em: bttp://www.letras.ufmg.br/poslit

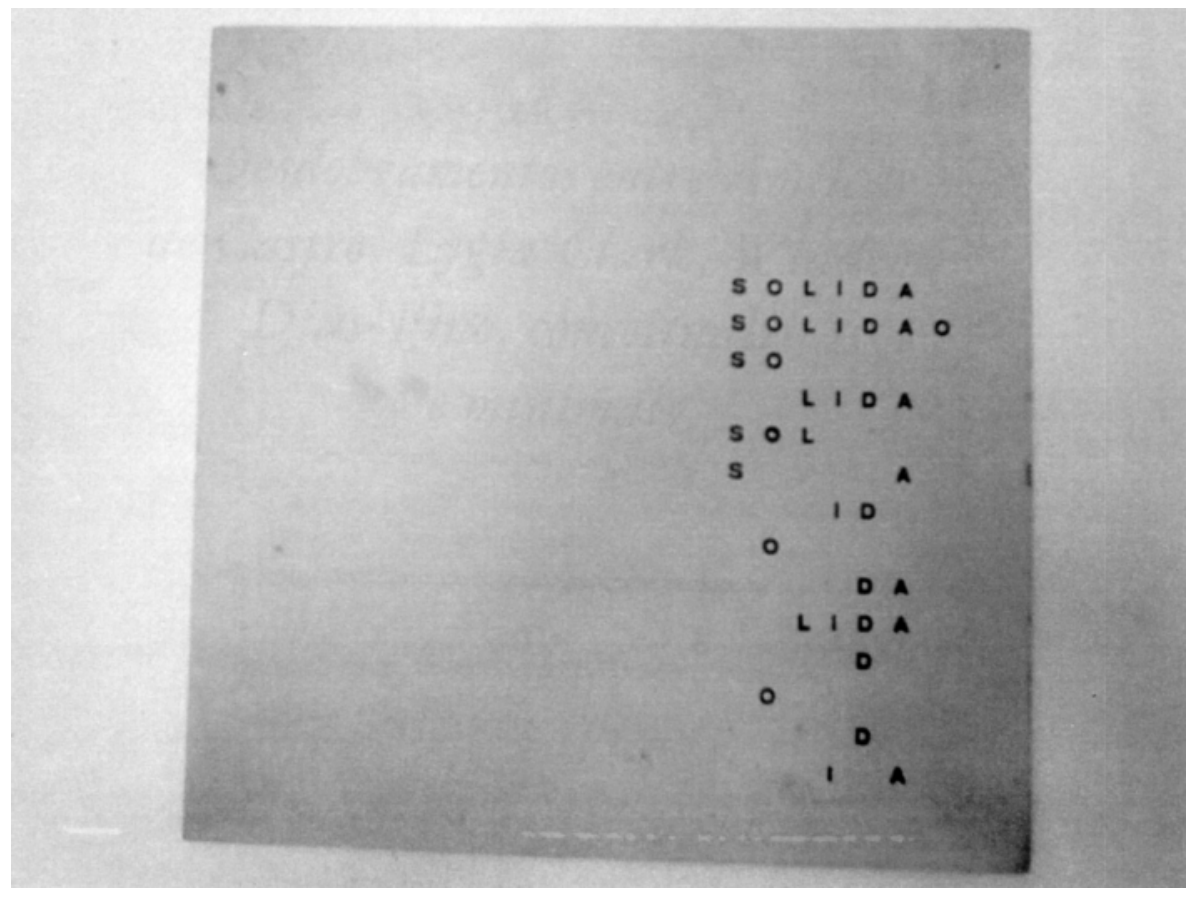

Figura 5 